\title{
Biotecnología y desarrollo. Avances de la agrobiotecnología en Argentina y Brasil
}

Graciela E. Gutman* y Pablo Lavarello**

\section{RESUMen}

Las producciones agroalimentarias constituyen uno de los principales sectores de aplicación de la moderna biotecnología (MB). De allí que países en desarrollo especializados en producciones basadas en recursos naturales (RRNN), como es el caso de Argentina y Brasil, constituyan un terreno privilegiado para la expansión y eventual desarrollo de nuevos productos y procesos basados en estas tecnologías. A partir de investigaciones propias (Argentina) y de estudios recientes sobre Brasil, el artículo explora las oportunidades que abre la $\mathrm{MB}$ en las producciones agroalimentarias y los desafíos que enfrentan estos países para avanzar en un sendero tecnológico e innovador sostenible. El artículo analiza las nuevas trayectorias tecnológicas, las bases del nuevo conocimiento científico y tecnológico, la organización industrial resultante y las estrategias de las firmas biotecnológicas líderes, así como las modalidades de difusión de la MB.

Número de clasificación: JEL: O33, O54, L16, L24

Palabras clave: moderna biotecnología, producciones agroalimentarias, Argentina, Brasil.

\section{Abstract}

Agro-food productions are one of the main diffusion for modern biotechnology (мв). For that reason, some developing countries specializing in natural resources based products, such as Argentina and Brazil, find the expansion and possible development of new products and processes based on these technologies attractive. Summarizing the results of own research (Argentina) and recent studies on Brazil, this attractive paper explores the opportunities that MB brings about in agro-food productions, and the challenges these countries must confront in order to reach a sustainable innovative and technological development. The article analyzes the new technological paths, the foundations of the new scientific and technological knowledge, the resulting industrial organization and firm strategies, as well as the patterns of MB diffusion in these countries.

Number of classification: JEL: O33, O54, L16, L24

Key words: modern biotechnology, agro-food production, Argentina, Brazil.

* Profesora de la Universidad Nacional de Buenos Aires, Argentina, e investigadora principal del CEUR-CONICET (Centro de Estudios Urbanos y Rurales-Consejo Nacional de Investigaciones Científicas) [gutman.graciela@gmail.com].

**Profesor de la Universidad Nacional de Buenos Aires, Argentina, e investigador del CEUR-CONICET. [plavarel@ciudad.com.ar]. 


\section{INTRODUCCIÓN}

Los países de América Latina ${ }^{1}$ se han caracterizado históricamente por tener una especialización productiva basada en sus recursos naturales. Durante el periodo de industrialización por sustitución de importaciones, los países de mayor tamaño relativo de la región - Brasil, Argentina - avanzaron hacia estructuras industriales más diversificadas. Sin embargo, las políticas de liberalización y desregulación puestas en marcha desde los años setenta condicionaron estos procesos de cambio estructural, y se consolidó un perfil de especialización basado en las ventajas comparativas.

Este perfil se vio acentuado desde los años noventa, impulsado por la dinámica de los mercados mundiales (aumentos en los precios internacionales impulsados por la demanda de países emergentes, notablemente China y los países del este asiático, y por el crecimiento de la demanda de biocombustibles) y los crecientes aumentos en la producción y la productividad en algunos complejos agroalimentarios, en particular los basados en soya y cereales. Estas dinámicas productivas son el resultado de importantes procesos de reestructuración tecnoproductiva y de innovaciones organizacionales e institucionales mayores.

La difusión de la moderna biotecnología (MB) ha tenido un papel clave como vector de transformación de los sistemas agroalimentarios. De manera convergente con otras tecnologías de punta como la bioinformática y, potencialmente, la nanotecnología, la MB conforma lo que varios autores consideran un nuevo paradigma tecnológico. ${ }^{2}$

El nuevo escenario tecnológico y productivo crea fuertes expectativas en países con producciones basadas en recursos naturales y plantea importantes interrogantes en relación con las potencialidades de la мв para promover el desarrollo y la diversificación productiva: ¿puede esperarse en los países analizados que la difusión del nuevo paradigma biotecnológico posibilite un proceso de cambio estructural que, partiendo de los patrones de especialización previa, se apoye en el desarrollo de capacidades científicas y tecnológicas? ¿Cuáles son los desafíos que enfrentan estos países para transformar las oportunidades biotecnológicas en esfuerzos efectivos?

\footnotetext{
${ }^{1}$ En este documento se habla indistintamente de América Latina y de la región.
}

${ }^{2}$ Se entiende por paradigma tecnológico, desde una perspectiva micoeconómica, un modo de solución de problemas tecnoeconómicos basado en un conjunto de conocimientos científicos y heurísticas seleccionados, contando con reglas orientadas a adquirir nuevos conocimientos e impedir su imitación por los competidores (Dosi, 1988).
Si se toman en cuenta los nuevos desafíos y potencialidades que plantea la moderna biotecnología, este artículo se propone avanzar en la búsqueda de algunas respuestas a las interrogantes enunciadas, a partir de la experiencia reciente de Argentina en la difusión de la MB en las producciones agroalimentarias, contrastándola con la de Brasil. ${ }^{3}$

La hipótesis que se sostiene en este artículo es la siguiente: frente a las oportunidades de la $\mathrm{MB}$, los países en desarrollo tienen dos posibles trayectorias, no necesariamente contrapuestas y probablemente secuenciales: o bien insertarse como adaptadores-difusores de un conjunto reducido de desarrollos en el marco de estrategias globales o bien avanzar hacia una diversificación de su perfil de especialización, profundizando la generación propia de innovaciones biotecnológicas. Estas alternativas se encuentran condicionadas por las estrategias de los agentes articuladores de las oportunidades que se presentan, por la existencia y grado de desarrollo de los activos complementarios locales y por las estrategias públicas en la articulación del Sistema de Ciencia y Técnica.

Los dos países analizados en este artículo presentan semejanzas y diferencias frente a estas alternativas, lo que ilustra diversos senderos posibles para el desarrollo de la MB y posibilita extraer enseñanzas para impulsar políticas de innovación tecnológica en otros países de la región.

El artículo aborda el análisis de algunos procesos y variables económicas e institucionales seleccionados. La consideración de otros temas tales como los impactos ambientales de la agrobiotecnología, el grado de aceptación por la sociedad de estas innovaciones o aspectos vinculados a la bioética - temas todos ellos de importancia en relación con los impactos socioeconómicos de la MBescapan a los alcances del mismo. En la sección II se analizan en forma estilizada y para el caso de la agrobiotecnología las nuevas trayectorias tecnológicas, las bases del nuevo conocimiento científico y tecnológico, la organización industrial resultante y las estrategias de las firmas biotecnológicas líderes en todo el mundo. En la sección III se resumen las modalidades de difusión de la moderna biotecnología en las producciones agroalimentarias de los países seleccionados en este artículo, con especial referencia al caso de Argentina. En la sección IV se analiza

${ }^{3} \mathrm{El}$ análisis de los desarrollos biotecnológicos en las producciones agroalimentarias de Argentina se apoya en recientes investigaciones que los autores realizaron, en equipo, en el marco del Programa de Investigaciones del CEUR-CONICET, la Universidad Nacional de General Sarmiento y la Universidad Nacional de Quilmes, "Los desarrollos de la moderna biotecnología en Argentina", que cuenta con el apoyo de la Agencia Nacional de Promoción Científica y Técnica (ANPCyT) y del Consejo Nacional de Investigaciones Científicas y Técnicas (CONICET), del ministerio de Ciencia Tecnología e Innovación Productiva de Argentina. Para el caso de Brasil se ha recurrido a investigaciones y publicaciones recientes sobre la temática. 
la brecha tecnológica presente en estos países, a partir de un conjunto relevante de indicadores. Finalmente, en las conclusiones se tratan las oportunidades que ofrece la moderna biotecnología en las producciones agroalimentarias y se presentan los desafíos que enfrentan países como Argentina y Brasil para alcanzar un desarrollo tecnológico e innovativo sostenible.

\section{LAS NUEVAS TRAYECTORIAS BIOTECNOLÓGICAS}

La moderna biotecnología, desarrollada a partir de mediados de los años setenta con el secuenciamiento del ADN, se caracteriza por un conjunto de características que se expresan en la configuración de los sistemas sectoriales de innovación (Ducos y Joly, 1988; Christensen, 2003; Arundel et al., 2006; Díaz y Golombek, 2004; Gutman et al., 2006 a), i) muestra una creciente interpenetración entre ciencia básica y tecnología, que dificulta la separación entre la investigación y el desarrollo, y requiere de nuevas formas de coordinación para la generación del conocimiento de base; $\mathrm{ii}$ ) abarca un amplio conjunto de tecnologías (basadas en el ADN recombinante, en la bioquímica o inmunoquímica y en el bioprocesamiento), lo que resulta en una base científica y tecnológica de naturaleza multidisciplinaria recombinatoria e integradora (que incluye una amplia variedad de disciplinas como la biología molecular, la química, la ingeniería bioquímica, la microbiología), con convergencia y sinergia con otras tecnologías de punta (informática, nanotecnología, tecnología de los materiales); iii) se trata de una tecnología genérica, transversal, que abarca una amplia gama de sectores productivos y de servicios; $i v$ ) tiene diversos grados de complementariedad y ruptura con tecnologías existentes en los sectores de aplicación, de allí la gran importancia que adquieren los activos complementarios; $v$ ) genera impactos económicos sistémicos a partir de las articulaciones entre proveedores, usuarios, prestadores de servicios, proveedores de bienes insumos especializados, industrias de envases y logística; vi) potencia las estrategias competitivas de las empresas usuarias mediante el desarrollo de productos de mayor valor, calidad y seguridad, de la disminución de los tiempos y costos de investigación y desarrollo (ID), y de los costos de producción y de transacción, convirtiéndose en fuente de ganancias diferenciales o rentas extraordinarias.

Estas tecnologías pueden cumplir distintos papeles en el proceso productivo: constituir la tecnología central (como los cultivos genéticamente modificados), asumir una función clave (como el uso de enzimas en los procesos de fermentación), o bien constituirse en una tecnología de soporte (como es el caso del uso de marcadores moleculares para controlar el crecimiento de plantas) (EC, 2007).
Las áreas de aplicación de la moderna biotecnología cubren un amplio rango de sectores económicos y de servicios; no obstante, en el ámbito mundial, los de mayor alcance actual son los desarrollos en medicina y salud humana y en las producciones agroalimentarias. ${ }^{4} \mathrm{El}$ sector de salud humana es el más importante, pues absorbe cerca de 87 por ciento del gasto total en ID biotecnológicas (Von Bevzekom y Arundel, 2006).

\section{Oportunidades de la moderna biotecnología en los sistemas agroalimentarios}

En la década de los setenta, diversos estudios preveían grandes oportunidades para la aplicación de la moderna biotecnología en los sistemas agroalimentarios (SAA); sin embargo, éstas no se manifestaron con la velocidad, profundidad y amplitud esperada (Goodman et al., 1987; Wilkinson, 1998). Desde mediados de los años ochenta, su difusión cobra un nuevo impulso a partir de las posibilidades que abren la ingeniería genética y la genómica para la identificación y desarrollo de nuevas características de insumos y productos.

En los SAA, la moderna biotecnología posibilita: $i$ ) aumentar la eficiencia y disminuir costos; ii) mejorar la calidad, seguridad y consistencia de los alimentos; iii) producir materias primas con cualidades específicas según sus usos industriales posteriores; $i v$ ) diversificar productos; $v$ ) mejorar los sistemas de control de calidad y seguridad; vi) potenciar las estrategias competitivas de las firmas al distribuir riesgos, y vii) disminuir tiempos y costos de ID (Gutman, Lavarello y Cajal, 2006 a). Sus aplicaciones en estos sectores abarcan un amplio espectro de posibilidades, como puede observarse en la gráfica 1, siendo las más importantes hasta el momento, en la producción agrícola, las derivadas de la ingeniería genética con la difusión en un número reducido de cultivos de semillas genéticamente modificadas, resistentes a herbicidas y a enfermedades, y más recientemente de semillas con genes "apilados" que las hacen resistentes a más de un elemento. En la producción ganadera, las innovaciones más difundidas están asociadas a vacunas, a la identificación de mapas genéticos y la clonación de animales. Otras posibilidades de aplicación de la MB en la agricultura, como las biotecnologías de la segunda generación (semillas con aptitudes específicas según su uso industrial posterior) o la utilización de biomasa para usos industriales, de desarrollo más

${ }^{4}$ Hacia fines de 2003 , la distribución por sectores de las empresas biotecnológicas en Estados Unidos era la siguiente: 60 por ciento en el sector salud humana, 33 por ciento en servicios; 5 por ciento en agrobiotecnología y 2 por ciento en medio ambiente. Los datos para la UE eran, respectivamente, 51, 35, 7 y 7 por ciento. (Gutman y Lavarello, 2008, tomado de EuropaBio, 2005). 
reciente, tienen amplio potencial en el futuro inmediato. Los usos de la MB en las industrias de la alimentación (enzimas recombinantes para los procesos de fermentación, nuevos alimentos funcionales, prebióticos y probióticos, y la aplicación de la мв para el control de calidad y seguridad de los alimentos) se encuentran en franca expansión.

GRÁFICA 1. Biotecnología en los sistemas agroalimentarios

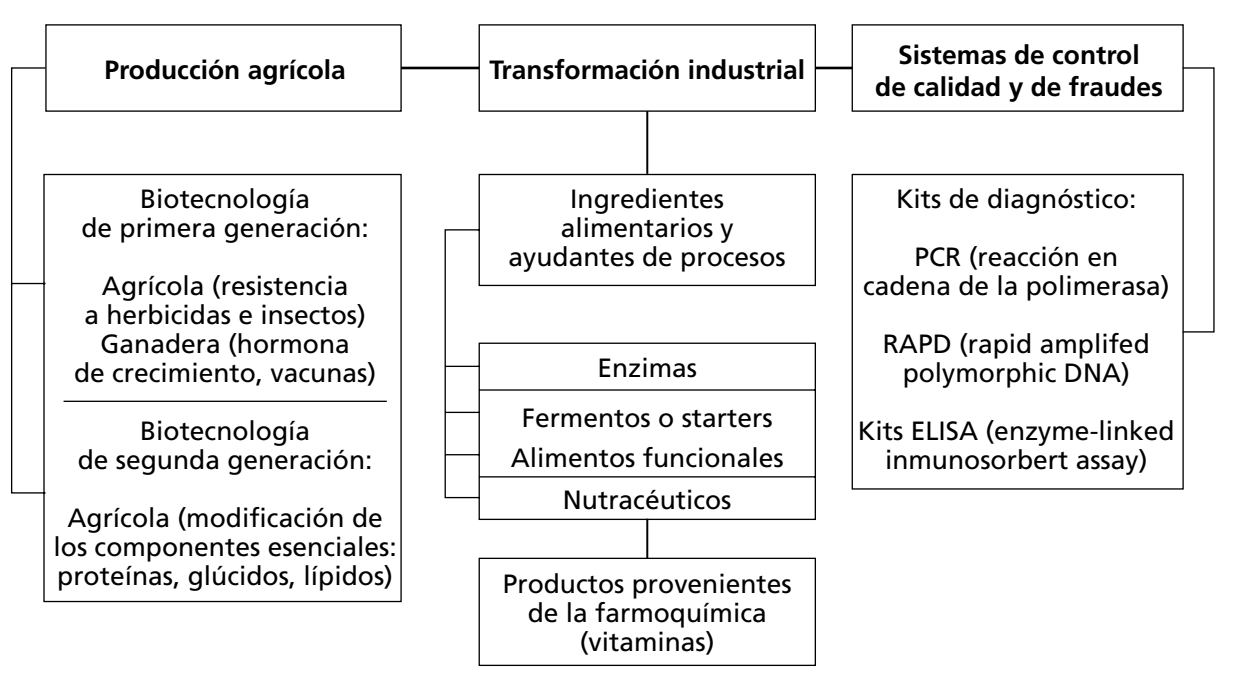

Fuente: Gutman, Lavarello y Cajal (2006 b).

Los avances de la moderna biotecnología en los sistemas agroalimentarios se han sustentado en gran medida -en particular en lo que se refiere a la generación de los conocimientos científicos de base- en innovaciones previas alcanzadas en las industrias químicas y de las farmacobiotecnologías (Ducos y Joly, 1988). Ello explica que, si bien las empresas especializadas en biotecnología agrícola tuvieron un papel relevante en el desarrollo de genes con resistencia a herbicidas, buena parte de las empresas centrales en la difusión de la agrobiotecnología consiste en grupos diversificados provenientes de la química, como es el caso de las empresas transnacionales (ETN) Dow Agrochemical, Du Pont, Syngenta, Monsanto y Bayer Crop Science. Estos grupos llevaron adelante una estrategia que combinó el desarrollo de capacidades propias y la conformación de alianzas con empresas especializadas en agrobiotecnología que luego absorbieron en la siguiente fase de difusión de la MB (Fransman, 1994). En una segun- da etapa, como se verá más adelante, se inició un proceso de especialización de las grandes firmas presentes en el sector.

\section{Modelos organizacionales e institucionales}

Los diversos modelos organizacionales resultantes de la difusión de la MB surgen de trayectorias tecnológicas diferenciadas en los diversos campos de aplicación de las mismas, asociadas al surgimiento de nuevas firmas, la reestructuración de las empresas existentes y la conformación de alianzas estratégicas. Estos cambios organizacionales se ven impulsados por cambios institucionales mayores en las modalidades de financiamiento de la ID y en los contextos regulatorios (formas deregulación de los derechos de propiedad intelectual), con fuertes impactos en las estrategias de las empresas líderes. En estos modelos participan, con mayor o menor importancia países y sectores (Arundel et al., 2006; Malerba y Orsenigo, 2002; Orsenigo, 1999; Pisano, 2006; Valentin y Jensen, 2003; Fransman, 1994):

i) organismos públicos de investigación, que incluyen universidades e institutos públicos de investigación;

ii) un nuevo segmento de empresas especializadas en biotecnología (EEB), en su mayoría spin-off universitarios, resultantes de la privatización de la infraestructura de ciencia y tecnología (СуТ), que actúan como interfase entre la investigación académica y la innovación industrial, explorando oportunidades de innovación, transformando el conocimiento científico en tecnológico y comercial, y proveyendo servicios especializados a las grandes empresas del sector;

iii) mercados de empresas de alta tecnología y desarrollo, capitales de riesgo (venture capital) y otras instituciones de financiamiento de la ID, que reducen los costos de transacción y proveen activos complementarios de gestión a las empresas especializadas en su fase de lanzamiento, y

iv) grandes empresas del sector (incumbents), total o parcialmente especializadas en la moderna biotecnología, que al inicio de la difusión del paradigma no cuentan con la amplitud de conocimientos científicos ni con las necesarias heurísticas.

La articulación de estos actores en un modelo organizacional se encuentra asociada a un proceso de "monetización (financierización) de la propiedad intelectual" que ha sido una fuerza poderosa en la configuración de las industrias 
biotecnológicas, principalmente en el sector de salud humana y en las agrobiotecnologías en Estados Unidos, y en el surgimiento de las EEB (Pisano, 2006; Orsi y Coriat, 2003). Este proceso fue impulsado por dos cambios reglamentarios: por un lado, la extensión del campo de los objetos patentables (patentes de organismos vivos), ${ }^{5}$ y la ampliación de los agentes suceptibles de patentar sus invenciones $^{6} \mathrm{y}$, por el otro, la posibilidad abierta a nuevas empresas para cotizar en el mercado de capitales a pesar de no registrar resultados económicos positivos.

El carácter genérico y transversal de la мB posibilitó, en un primer momento, estrategias de diversificación por parte de las grandes empresas establecidas, que valorizaron sus ventajas tecnológicas en varias áreas de aplicación: fármacos, alimentos, semillas genéticamente modificadas. De allí surgieron las llamadas industrias de las "ciencias de la vida", que incorporaron rápidamente las modernas biotecnologías para su aplicación en una extensa gama de productos, con potencial para disputar las capacidades de diferenciación de productos finales.

En el marco de este proceso de diferenciación de capitales se va consolidando un sector de biotecnología agrícola conformado por empresas de distinto tamaño y base tecnológica: grandes empresas de agroquímicos y productos farmacéuticos, empresas semilleras y empresas especializadas en biotecnología, en una dinámica basada en estrategias de "apropiación" de las etapas y actividades de la producción agropecuaria por el capital industrial. ${ }^{7}$

Si bien inicialmente los desarrollos de la agrobiotecnología reproducen la dinámica industrial registrada en la farmabiotecnología, en la cual coexisten grandes empresas y pequeñas firmas especializadas en el marco de mercados de conocimiento, su evolución posterior mostrará una tendencia hacia la concentración asociada, por un lado, al reforzamiento de las barreras que se oponen a la entrada "aguas arriba", impulsado por la posibilidad de patentamiento de los genes y el consecuente control de las variedades de los principales cultivos; y por el otro, a las estrategias de alianzas y fusiones, por parte de las empresas de agroquímicos que les permitirán valorar su ID a partir de la integración "aguas abajo" de activos complementarios y redes comerciales.

${ }^{5}$ A partir del caso Diamond vs. Chakabarty, la Suprema Corte de Justicia de Estados Unidos permitió la protección mediante patentes de tejidos vivos. Este caso luego fue extendido a la posibilidad de patentar material genético (Oehmke y Wolf, 2003).

${ }^{6}$ En Estados Unidos, la Bayh Dole Act de 1980 permitió a instituciones públicas de $c$ y $T$ patentar sus investigaciones.

7 "La apropiación" de etapas y procesos de la producción agropecuaria y "sustitución" de productos agrí́colas por otros provenientes de la industria son conceptos desarrollados en Goodman et al. 1987, para analizar la dinámica de industrialización de la agricultura.
Los costos y tiempos de las actividades regulatorias constituyen asimismo importantes barreras a la entrada. De allí que las capacidades de las empresas en materia regulatoria constituyan importantes activos complementarios. En efecto, la introducción de una nueva semilla no sólo involucra superar las estrategias de patente de las empresas dominantes en el mercado; enfrenta también exigencias regulatorias desde la etapa de experimentación hasta el consumo final, que apuntan a minimizar los riesgos sanitarios, ambientales y de inocuidad que podrían surgir del uso de organismos genéticamente modificados. Estas exigencias se traducen en altos costos y tiempos de lanzamiento para las nuevas semillas, que se ven multiplicados en función del número de países importadores de la tecnología y de los productos finales. Por ello, el análisis y la evaluación de los diversos aspectos y costos regulatorios acompañan el desarrollo del producto desde sus inicios. ${ }^{8}$

El reforzamiento reciente de las condiciones legales de apropiabilidad y las mayores exigencias regulatorias para su producción y comercialización refuerzan las altas barreras de entrada en estos mercados. Son pocas las empresas que pueden enfrentar estos costos. Para los tres cultivos en los que se difundió más fuertemente la biotecnología, algodón, maíz y soya, los desarrollos se concentran en un conjunto reducido de genes cuyas patentes son propiedad de cuatro empresas que cuentan con las capacidades regulatorias para valorar esta tecnología a escala global (Ward, 2000).

A priori sería posible argumentar que existen importantes oportunidades que permitirían desarrollar semillas transgénicas con características particulares para reemplazar a las existentes. En materia de biotecnologías de la primera generación (inputs traits), sin embargo, los desarrollos de nuevos genes no hacen obsoletos a los existentes. Tampoco es clara la posibilidad de inventar en el entorno de las patentes existentes - por ejemplo un gen alternativo al de resistencia al glifosato-.${ }^{9}$ Aun siendo posible el caso, la difusión del insumo complementario genera nuevas barreras: el gen de Monsanto es resistente a la marca de RR, con

${ }^{8}$ Más allá de las particularidades nacionales, la aprobación de una semilla transgénica abarca varias etapas, asociadas a los problemas de bioseguridad: $i$ ) Las etapas de aprobación para la experimentación y para liberación al medio de las variedades desarrolladas en laboratorio. En las mismas se evalúan los impactos potenciales sobre el ecosistema, las características biológicas del organismo y evalúan los impactos potenciales sobre el ecosistema, las características biológicas del organismo ga el monitoreo sobre los efectos en el medio ambiente o la inocuidad no identificados en las fases previas. Además, en ciertos países importadores, dada la presión de organizaciones de consumidores y otras organizaciones no gubernamentales, se ha difundido el empleo de etiquetas en los productos transformados a partir de cultivos transgénicos, lo que implica costos adicionales, y afecta la gobernanza de las cadenas (Trigo et al., 2002).

${ }^{9}$ Innovar en torno de la semilla Bt resistente a insectos también resulta difícil. De los 98 tipos de 
amplio volumen de ventas y por lo tanto sujeto a importantes efectos "candado" (lock in) (Oehmke y Wolf, 2003). En cambio, en las biotecnologías de segunda generación orientadas a modificar componentes esenciales de las materias primas para su posterior uso industrial (output traits, véase más adelante la gráfica 2), las oportunidades de nuevos desarrollos son mayores. Los mismos tienen importantes efectos en las estrategias de diferenciación de productores industriales, aunque están condicionados a una mayor coordinación entre distintos actores aguas abajo en la cadena de valor.

De allí que las posibilidades de desarrollos de genes patentables por nuevas empresas se dirijan en gran medida hacia las biotecnologías de segunda generación. En un contexto de condiciones fuertes de apropiabilidad, un reducido número de genes -independientemente del número de empresas existentes- conduce a un exceso de concentración y limita las oportunidades de entrada de nuevas empresas. En los últimos años, las empresas han reforzado las barreras a la entrada con estrategias de "apilamiento" de genes a partir de desarrollos anteriores (por ejemplo, maíz resistente tanto a herbicidas como a insectos). Estas innovaciones seguramente se basarán en la(s) patente(s) de los titulares previos (ASA, 2008). De esta forma, la dinámica schumpeteriana, según la cual cada nueva oleada de productos hace obsoleta y reemplaza a la previa, no tiende a verificarse.

Dentro de este sendero, en los últimos veinte años emerge un sector proveedor de insumos agrícolas en el marco de importantes procesos de concentración y centralización empresarial. Pueden distinguirse dos etapas en las estrategias de las empresas de biotecnología agrícola (Chataway et al., 2003):

1) Entre mediados de los ochenta y mediados de los noventa, una etapa de exploración y de inversiones en ID a partir de la conformación de alianzas estratégicas entre empresas agroquímicas y empresas especializadas en biotecnología, a las que se sumaron las grandes empresas transnacionales de farmoquímica para el desarrollo de semillas transgénicas resistentes a herbicidas y enfermedades; algunos ejemplos de esta estrategia son: las alianzas entre Monsanto y Millenium Pharmaceutical; la alianza y posterior adquisición de Calgene también por parte de Monsanto, y la alianza y posterior adquisición de Plant Genetic System por parte de AgrEvo (Aventis).

2) Desde mediados de los noventa, una etapa de consolidación y absorción de activos complementarios, concentrada en la búsqueda de com

toxinas $\mathrm{Bt}$ existentes, sólo se liberaron para comercializar seis, que se encuentran bajo patente de Monsanto (4), Dow (1) y Aventis (1) (Oehmke y Wolf, 2003). plementariedades entre los agroquímicos y las empresas de semillas, y en el desarrollo de paquetes agronómicos que reforzaron los procesos de concentración. Éstos son los casos, entre otros, de las adquisiciones de Dekalb, Asgrow y la división de semillas de Cargill por parte de Monsanto, o de la compra de Pionner e Hybrinova por parte de Du Pont.

Las grandes empresas continuaron más tarde - a fines de los años noventa - esta reorientación estratégica con una modificación de su estructura organizacional, al separar sus divisiones farmacéuticas de las de agrobiotecnología. Estas últimas aceleraron sus fusiones con empresas semilleras y otras actividades del agronegocio "aguas abajo". ${ }^{10}$ Esto se evidenció en importantes escisiones en las estructuras empresariales, como es el caso de la separación de la división de semillas de Novartis y Zeneca, para formar Syngenta en 1999 (Chataway et al. 2003; Ward, 2000; Bisang y Varela, 2006).

Esta mayor especialización es consistente, por un lado, con un elevado coeficiente de inversiones en ID de estas empresas transnacionales (ETN), uno de los más altos dentro del sector industrial, que indica la importancia de sus estrategias tecnológicas, y, por el otro, con el bajo peso de los activos físicos asociados a las economías de escala tradicionales. En forma simultánea, un conjunto de empresas de base química (Du Pont, Basf, Dow Chemical) mantiene un alto grado de diversificación y activos físicos integrando los desarrollos biotecnológicos en sus divisiones de agroquímicos. Puede observarse en el cuadro 1 que la incursión de las industrias químicas en la biotecnología no se limita a la provisión de insumos agrícolas, sino que existen empresas que se orientan a proveer ingredientes a las industrias alimentarias. Ello muestra una dinámica de diversificación industrial de la químicofarmacéutica que se inserta en distintas etapas de los subsistemas alimentarios, influyendo en la dirección y el ritmo del cambio tecnológico.

De esta forma se consolida una organización industrial en la cual coexisten grandes empresas transnacionales químicas diversificadas hacia el área de biotecnología, y otras escindidas de los grupos de farmabiotecnología o quími cos, que adoptan una activa estrategia de externalización de inversiones físicas.

${ }^{10} \mathrm{El}$ caso de Estados Unidos es ilustrativo al respecto: de las 16 empresas especializadas en biotecnología agrícola existentes a mediados de 1985, sólo quedaban seis empresas independientes en 2000, mientras que las empresas semilleras se redujeron de 10 a sólo dos. En ambos casos, estas empresas fueron absorbidas por las empresas transnacionales (ETN) de agrobiotecnología y de agroempresas fueron absorbidas por las empresas transnacionales (ETN) de agrobiotecnología y de agro-
químicos. Adicionalmente, las adquisiciones de EEB posibilitaron a las ETN de biotecnología agrícola el acceso al portafolio completo de patentes de estas empresas especializadas (Schimmelpfennig y King, 2004). 
Ambos segmentos se transforman en nuevos centros coordinadores de redes de alianzas y adquisiciones de empresas especializadas en biotecnología. ${ }^{11}$

CUAdro 1. Principales Etn en los SAA, año 2006

\begin{tabular}{|c|l|c|c|c|c|}
\hline Industria & \multicolumn{1}{|c|}{$\begin{array}{c}\text { Nombre (y origen } \\
\text { tecnológico) }\end{array}$} & $\begin{array}{c}\text { Ventas } \\
\text { (millo- } \\
\text { nes de } \\
\text { dólares) }\end{array}$ & $\begin{array}{c}\text { Inversión } \\
\text { ID por } \\
\text { ciento } \\
\text { (ventas) } \\
\text { (1) }\end{array}$ & $\begin{array}{c}\text { Inversión } \\
\text { activo fijo } \\
\text { por ciento } \\
\text { (ventas) } \\
\text { (2) }\end{array}$ & $\begin{array}{c}\text { Activos } \\
\text { fijos/ } \\
\text { ID } \\
\text { (2/1)* }\end{array}$ \\
\hline \multirow{4}{*}{$\begin{array}{c}\text { Agroquí- } \\
\text { micos/ } \\
\text { semillas }\end{array}$} & $\begin{array}{l}\text { Syngenta (farmacéu- } \\
\text { tica) }\end{array}$ & 8,582 & 10.1 & 2.2 & 0.2 \\
\cline { 2 - 6 } & Bayer (química) & 2,356 & 6.9 & 4.7 & 0.7 \\
\cline { 2 - 6 } & Du Pont (química) & 1,415 & 5 & 5 & 1.0 \\
\cline { 2 - 6 } & BASF (química) & 1,357 & 2.5 & 5.2 & 2.1 \\
\cline { 2 - 6 } & Dow Chemical (química) & 1,136 & 2.3 & 3.5 & 1.5 \\
\hline \multirow{4}{*}{$\begin{array}{l}\text { Ingredientes } \\
\text { alimentarios }\end{array}$} & Monsanto (química) & 6,665 & 9.3 & 4.5 & 0.5 \\
\cline { 2 - 6 } & Novozymes (farmacéutica) & 1,053 & 12.6 & 5.7 & 0.5 \\
\cline { 2 - 6 } & Danisco (alimentaria) & 3,502 & 4.5 & 5.2 & 1.2 \\
\cline { 2 - 6 } & DSM (química) & 10,238 & 3.5 & 4.7 & 1.3 \\
\cline { 2 - 6 } & Ajinomoto (alimentaria) & 9,627 & 2.7 & 4.9 & 1.8 \\
\hline
\end{tabular}

* Indicador proxy de la importancia de los activos físicos en relación con ID biotecnológicos. Fuente: Elaboración propia a partir de Gutman y Lavarello (2008).

Al mismo tiempo, buena parte del "paquete tecnológico" queda en manos de las mismas grandes empresas. ${ }^{12}$ Syngenta, Bayer, Du Pont y Monsanto, cuatro de las mayores empresas del sector, integran la producción de semillas y agroquímicos; las dos primeras con una participación de las semillas en las ventas conjuntas de estos insumos de menos de 20 por ciento, y las dos últimas con alrededor de la mitad o más de las ventas agrobiotecnológicas concentradas en semillas.

\footnotetext{
${ }^{11}$ Trigo et al. (2002) señalan que, si bien entre 1997 y 2000 se realizaron cerca de 100 alianzas en ID entre grandes ETN y centros de investigación, invirtiendo varios miles de millones de dólares, sólo unos pocos productos llegaron al mercado y sólo tres han sido ampliamente adoptados (soya RR, maíz Bt y algodón Bt).

${ }^{12}$ Por paquete tecnológico se entiende en este documento el control por parte de ETN de tecnologías asociadas (semillas y herbicidas, por ejemplo).
}

\section{DIFUSIÓN DE LA MODERNA BIOTECNOLOGÍA EN LOS SAA DE AmÉrica Latina}

Las actividades agroalimentarias se encuentran entre los principales sectores de aplicación de la мB. De allí que varios países de América Latina en los que las producciones basadas en recursos naturales forman parte central de sus perfiles de especialización, constituyan un terreno privilegiado para la expansión y eventual desarrollo de nuevos productos y procesos basados en estas tecnologías. ${ }^{13}$

Argentina y Brasil han sido los países de América Latina en los que se ha registrado una mayor difusión de la MB en la producción agrícola, a partir de las estrategias de empresas transnacionales productoras y proveedoras de semillas genéticamente modificadas y agroquímicos, en una dinámica asociada a la adopción de nuevos sistemas o paquetes tecnológicos.

Argentina es el país de la región que ha adoptado en forma más rápida estas tecnologías. La superficie sembrada con cultivos transgénicos en 2006 llegó a 18 millones de ha. y junto con Brasil (11 millones), secunda a Estados Unidos en la difusión de cultivos agrícolas genéticamente modificados. El grado de difusión de la MB en los tres principales cultivos en Argentina es, en el caso de la soya, de más de 90 por ciento de la superficie sembrada; en maíz, 73 por ciento del área cultivada, y en algodón 80 por ciento. Si consideramos el total de hectáreas sembradas con cultivos genéticamente modificados (GM), Argentina posee la mayor proporción del área cultivada total dedicada a cultivos transgénicos (61 por ciento), seguida por Estados Unidos (29 por ciento) y Brasil (16 por ciento) (James, 2006).

Dado el alto ritmo y nivel de adopción de semillas GM en Argentina, un análisis detallado de la misma permite ilustrar la importancia y la secuencia temporal de la difusión de la MB. Diversos trabajos han analizado el impacto de la difusión de estas tecnologías en la rentabilidad de los productores (entre otros, Qaim y Traxler, 2002; Trigo et al., 2002). Un análisis comparado del impacto en Argentina de la difusión de la biotecnología en soya, algodón y maíz muestra un efecto sobre las ganancias acumuladas por los productores de más de $10 \mathrm{mil} \mathrm{mi-}$ llones de dólares entre 1996 y 2004, explicado en 95 por ciento por la difusión de la soya RR (round up ready) y por la posibilidad de doble ciclo anual de este cultivo. El mencionado impacto es ligeramente inferior al de Estados Unidos (10,700 millones) pero 10 veces superior al de Brasil (Brookes y Barfoot, 2005).

\footnotetext{
${ }^{13}$ La participación de los sistemas agroalimentarios (incluyendo producción primaria y procesamiento industrial) en el PIB es alrededor de 32 por ciento en Argentina, Colombia y Chile y de 27 por ciento en Brasil (IICA, 2004).
} 
CUADRO 2. Superficie sembrada con cultivos transgénicos por país, 1996-2006 (millones de hectáreas)

\begin{tabular}{|c|c|c|c|c|c|c|c|c|c|c|c|}
\hline País & 1996 & 1997 & 1998 & 1999 & 2000 & 2001 & 2002 & 2003 & 2004 & 2005 & 2006 \\
\hline EUA & 1.5 & 8.1 & 20.5 & 28.7 & 30.3 & 35.7 & 39 & 42.8 & 47.6 & 49.8 & 54.6 \\
\hline $\begin{array}{l}\text { Argen- } \\
\text { tina }\end{array}$ & 0.1 & 1.4 & 4.3 & 6.7 & 10 & 11.8 & 13.5 & 13.9 & 16.2 & 17.1 & 17.1 \\
\hline Brasil & " & " & " & $"$ & " & $"$ & 3.5 & 3 & 5 & 9.4 & 9.4 \\
\hline Canadá & 0.1 & 1.3 & 2.8 & 4 & 3 & 3.2 & $"$ & 4.4 & 5.4 & 5.8 & 5.8 \\
\hline China & 1.1 & 1.8 & n.a. & 0.3 & 0.5 & 1.5 & 2.1 & 2.8 & 3.7 & 3.3 & 3.5 \\
\hline India & $"$ & $"$ & $"$ & $"$ & $"$ & $"$ & $<0.1$ & 0.1 & 0.5 & 1.3 & 3.8 \\
\hline $\begin{array}{l}\text { Para- } \\
\text { guay }\end{array}$ & $"$ & $"$ & $"$ & $<0.1$ & 0 & 0.3 & 0.5 & 0.7 & 1.2 & 1.8 & 2.0 \\
\hline Australia & $"$ & 0.1 & 0.1 & $"$ & 0.1 & 0.2 & " & 0.1 & 0.2 & 0.3 & 2 \\
\hline México & $"$ & $"$ & $<0.1$ & $<0.1$ & $"$ & $<0.1$ & $<0.1$ & $<0.1$ & 0.1 & 0.1 & $s / d$ \\
\hline España & $"$ & $"$ & $<0.1$ & $<0.1$ & $"$ & $<0.1$ & $<0.1$ & $<0.1$ & 0.1 & 0.1 & $s / d$ \\
\hline $\begin{array}{l}\text { Alema- } \\
\text { nia }\end{array}$ & $"$ & $"$ & $"$ & $"$ & $"$ & $<0.1$ & $<0.1$ & $<0.1$ & $<0.1$ & $<0.1$ & $s / d$ \\
\hline Portugal & $"$ & $"$ & $"$ & $<0.1$ & $"$ & $"$ & $"$ & $"$ & $"$ & $<0.1$ & $s / d$ \\
\hline Francia & $"$ & $"$ & $<0.1$ & $<0.1$ & $"$ & $"$ & $"$ & $"$ & $"$ & $<0.1$ & $s / d$ \\
\hline $\begin{array}{l}\text { Repúbli- } \\
\text { ca Checa }\end{array}$ & $"$ & $"$ & $"$ & $"$ & $"$ & $"$ & $"$ & $"$ & $"$ & $<0.1$ & $s / d$ \\
\hline Otros & $"$ & $"$ & $"$ & $"$ & $"$ & $"$ & $"$ & $"$ & $"$ & 2.8 & $s / d$ \\
\hline Total & 2.8 & 12.7 & 27.8 & 39.9 & 44.2 & 52.6 & 58.7 & 67.7 & 81 & 90 & 102 \\
\hline
\end{tabular}

Fuente: OCDE (2006) a partir de Clive James, 1997 y 1999. Global Review of Transgenic Crops, ISAA Briefs, The International Service of the Acquisition of Agro-biotech Applications (ISAAA), Ithaca, Nueva York; Clive James (2006), Global.

Este proceso de aumento notable en las "rentas tecnológicas" internalizadas en gran parte por el productor, pero apropiadas en buena medida por las grandes ETN de semillas e insumos, no surge de una innovación aislada, sino que resulta de la convergencia de distintas trayectorias complementarias en lo que se ha denominado un nuevo sistema técnico o "paquete" compuesto por tres conjuntos de tecnologías complementarias: siembra directa, semillas transgénicas y uso de herbi- cidas específicos (glifosato). La adopción del mencionado paquete en Argentina se manifestó en un proceso de incorporación secuencial de cada una de las tecnologías, que es posible presentar en forma estilizada (Gutman et al., 2008):

- En un primer momento, el vector del cambio en el sistema tecnológico del agro argentino estuvo asociado al desarrollo de nuevas técnicas de siembra directa (SD). La misma consiste en sembrar reduciendo sustantivamente las actividades de labranza, sin roturar la tierra, con una sensible disminución en los costos de producción directos y del empleo. Estas técnicas están parcialmente incorporadas a la maquinaria agrícola y comprenden cambios en los procesos de siembra y poscosecha por parte de los agricultores. ${ }^{14}$ Las limitaciones mayores de estas técnicas estaban asociadas a la ausencia de un herbicida genérico para el control de malezas, por lo que su difusión requería la adopción de herbicidas complementarios.

- En un segundo momento, desde mediados de los años noventa, estas limitaciones fueron superadas con la adopción de insumos biotecnológicos, lo que abrió una nueva etapa en este proceso que explica la aceleración en la difusión de las técnicas de SD. El nuevo paquete consistía en una semilla -la soya RR- resistente al glifosato, que simplifica el proceso de aplicación y posibilita ahorros de costos (entre 24 y 30 dólares por hectárea; Trigo et al., 2002).

- En forma complementaria, la difusión de la siembra directa y el paquete soya-glifosato se tradujo en un cambio de los requerimientos de los distintos equipos y maquinarias agrícolas convencionalmente utilizados. Esto resultó en un conjunto de adaptaciones e innovaciones incrementales que realimentaron la reducción de costos.

El conjunto de innovaciones acumulativas se traduce en irreversibilidades técnicas y económicas. Cuando en 1997 los precios internacionales cayeron significativamente, el sector agropecuario argentino se encontraba muy endeudado por la compra de nuevos equipos y la adopción de las innovaciones biotecnológicas.

${ }^{14}$ La difusión de la siembra directa ha sido el resultado de una conjunción de esfuerzos públicos y privados. Los primeros grupos de estudio sobre la posibilidad de difusión de siembra directa en el país se iniciaron en los años setenta en el ámbito del Instituto Nacional de Tecnología Agropecuaria (INTA). En esa época se realizó el primer ensayo dinamométrico, en la Universidad Nacional de La Plata, para determinar el consumo energético de las máquinas sembradoras para siembra directa (Maroni, 1999). 
GRÁFICA 2. Argentina: difusión de la siembra directa por cultivo (Millones de hectareas)

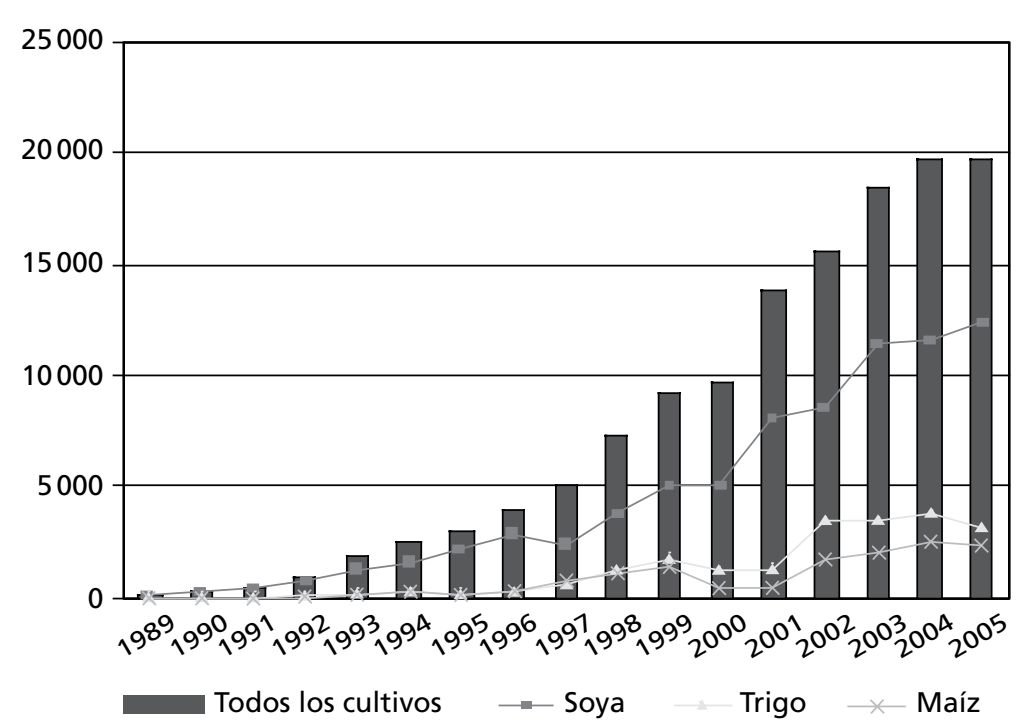

Fuente: Elaboración propia con base en información de la Asociación Argentina de Productores en Siembra Directa (AAPRESID) y de la Encuesta Nacional Agropecuaria del Instituto Nacional de Estadística y Censos (INDEC)

A pesar de ello, no sólo se reforzó el proceso de concentración en el agro, pese al refinanciamiento operado por la banca pública, sino que se otorgó un impulso adicional a la difusión del nuevo paquete tecnológico reductor de costos de labranza. Estas irreversibilidades fueron acompañadas por inversiones llevadas a cabo por los proveedores de insumos y equipos. Como consecuencia de ello, el cambio en los precios relativos se tradujo en un reforzamiento de las trayectorias tecnológicas previas, lo que se evidenció en el aumento de la superficie con siembra directa. Ésta se triplicó entre 1997 y 2002, en un contexto desfavorable para el sector.

Uno de los factores centrales que explican la rápida absorción de las nuevas tecnologías es el marco institucional existente en Argentina, caracterizado por un contexto regulatorio flexible y una amplia infraestructura tecnológica que tuvo un importante papel en la etapa de adaptación de las nuevas tecnologías a las condiciones locales (Gutman, Lavarello y Roisinblit, 2006).

La dinámica registrada confirma las especificidades señaladas por varios autores, en relación con las características del desarrollo tecnológico en el agro (Pavitt, 1984; Possas et al., 1996). En este sector, la innovación (bio)tec- nológica se encuentra básicamente determinada por la adopción de nuevos equipos e insumos intensivos en ciencia y tecnología. El principal vector de difusión de la tecnología está asociado a la presencia local de los denominados "sectores difusores de conocimiento", tales como las industrias de insumos biotecnológicos y fundamentalmente la de maquinaria agrícola, cuyo sendero evolutivo tiene su origen en la fase de industrialización sustitutiva de importaciones (Gutman et al., 2008). El cambio de paradigma tecnológico no resulta en el desplazamiento de las trayectorias tecnológicas previas, sino en una convergencia con éstas.

Acompañando la difusión de las MB en la etapa agrícola, se produjo en Argentina y Brasil una fuerte reestructuración de los mercados de agroquímicos y de semillas, con el aumento y la concentración de la oferta de insumos biotecnológicos en pocas empresas privadas de los agronegocios, en su mayoría ETN líderes mundiales, fuertemente atraídas por las condiciones productivas e institucionales locales y por la presencia de importantes activos complementarios: disponibilidad de recursos naturales, capacidades de molienda y logística, y una infraestructura de ciencia y tecnología que permitía la adaptación de los paquetes biotecnológicos a las variedades locales.

En el caso de Brasil, a finales de los noventa, por lo menos 22 empresas de capitales locales fueron compradas por ETN, siguiendo la estrategia de fusiones $\mathrm{y}$ adquisiciones en el nivel mundial, entre ellas cuatro empresas adquiridas por Monsanto, una por Du Pont, cuatro por Aventis y cinco por Dow AgroScience (Genoma España, 2005). La legislación brasileña en relación con los derechos de propiedad intelectual en semillas, al reconocer el derecho del comprador sobre las variedades esencialmente derivadas, fue un factor de atracción particular para las firmas que se instalaron en el país (Salles-Filho, 2007).

Los sistemas locales de innovación han desempeñado un importante papel en la adaptación y extensión de estos paquetes. Adicionalmente existen en ambos países aprendizajes institucionales cruciales para la organización de las redes de distribución (sistemas de identidad preservada, trazabilidad, difusión de estándares internacionales, certificación de calidad) que se ven acompañados de cambios organizacionales profundos asociados a la expansión de fondos financieros de inversión y de nuevos agentes que invierten en el agro basándose en la contratación de servicios y el alquiler de tierras. ${ }^{15}$

A pesar de estos importantes senderos innovativos en el agro, las estrate-

${ }^{15}$ Es el caso particular de Argentina, en donde la expansión de la soya estuvo acompañada por la incursión en el sector de fondos de inversión y de "pools de siembra", conformados por capitales mayoritariamente extrasectoriales, con una lógica organizativa basada en el alquiler de tierras y la contratación de servicios (de siembra, de cosecha y otros servicios técnicos especializados). 
gias de las empresas transnacionales se han centrado en la difusión de paquetes tecnológicos con limitados esfuerzos locales. Las actividades centrales de ID de estas empresas transnacionales presentes en su mayoría en ambos países (Monsanto, Syngenta Dow AgroScience, Bayer y Du Pont, entre otras) se concentran casi con exclusividad en las casas matrices y tienen pocas filiales tecnológicas fuera de su lugar de origen. Localmente, estas empresas realizan actividades de adaptación de sus desarrollos biotecnológicos a las condiciones edafológicas y climáticas, además de cumplir con los requisitos regulatorios locales (Bisang et al., 2006). Es importante que estos esfuerzos adaptativos y regulatorios se combinan con una activa estrategia de exploración, selección y apropiación de conocimientos científicos y tecnológicos, y de variedades en el marco de sus estrategias globales de ID.

De esta forma, las ETN se convierten en los nodos articuladores del sistema técnico a partir del control de la tecnología central (en este caso, la MB). La constitución de estos "paquetes tecnológicos" tiene un impacto central no sólo en el armado de los sistemas técnicos de los productores agropecuarios, sino y principalmente sobre las articulaciones posteriores con otras tecnologías, y por lo tanto sobre sus posibilidades de definir en forma autónoma estrategias de producción de bienes más complejos y de mayor valor (upgrading) y de diversificación tecnológica.

En resumen, el impacto económico de la biotecnología se encuentra asociado a la expansión de unos pocos pero relevantes cultivos agrícolas en el marco de importantes trayectorias tecnológicas previas en tecnologías complementarias, aunque muy condicionado por las estrategias tecnológicas de grandes empresas transnacionales y por el bajo desarrollo de las capacidades locales.

\section{CaPaCidades biotecnológicas, deSEMPeÑo Y deSAFíos}

Brasil (con un mayor grado de desarrollo) y Argentina obtuvieron hasta los años ochenta un avance importante en la construcción de capacidades biotecnológicas, que los colocó entre los pocos países en desarrollo con innovaciones en dichas áreas. Desde los años noventa, el estancamiento de la inversión en ID en estos países contrasta con el esfuerzo tecnológico realizado por otros países desarrollados y en desarrollo. En Brasil y Argentina, así como en otros países de América Latina, la inversión bruta en ID como porcentaje del producto interno bruto no superó en estos años el 1 por ciento, no sólo menor al alcanzado por países desarrollados como Estados Unidos y Canadá (2.7 por ciento), sino tam- bién al de otros países en desarrollo, como China (1.25 por ciento), Corea del Sur (3 por ciento) o Singapur (2.4 por ciento) (RICyT, 2008).

A pesar de esta importante brecha en esfuerzos tecnológicos generales, en el área de las biotecnologías las bases científicas y empresariales de Argentina y Brasil aún son comparables a las de China e India en términos de publicaciones y empresas biotecnológicas per capita (cuadro 3).

CUADRo 3. Indicadores de capacidades biotecnológicas y desempeño (Países seleccionados)

\begin{tabular}{|l|c|c|c|c|c|c|}
\hline & $\begin{array}{l}\text { Estados } \\
\text { Unidos }\end{array}$ & China & India & Singapur & Brasil & Argentina \\
\hline $\begin{array}{l}\text { Investigadores en biología } \\
\text { y disciplinas conexas 2000 }\end{array}$ & 446,890 & 50,000 & $\mathrm{~s} / \mathrm{d}$ & 1,000 & 20,233 & 9587 \\
\hline $\begin{array}{l}\text { Diplomas de doctorado en biología } \\
\text { y disciplinas conexas en EUA, 2000-2003 }\end{array}$ & $\mathrm{s} / \mathrm{d}$ & 3,716 & 838 & $\mathrm{~s} / \mathrm{d}$ & 189 & 97 \\
\hline $\begin{array}{l}\text { Empresas “core" biotecnológicas } \\
\text { (2002-2003) }\end{array}$ & 1,457 & 136 & 96 & $\mathrm{~s} / \mathrm{d}$ & 213 & 84 \\
\hline - Salud humana & 947 & 86 & $\mathrm{~s} / \mathrm{d}$ & $\mathrm{s} / \mathrm{d}$ & 140 & 20 \\
\hline - Agropecuario & 175 & 23 & $\mathrm{~s} / \mathrm{d}$ & $\mathrm{s} / \mathrm{d}$ & 65 & 54 \\
\hline - IAA, industrial, otros & 335 & 27 & $\mathrm{~s} / \mathrm{d}$ & $\mathrm{s} / \mathrm{d}$ & 8 & 10 * \\
\hline $\begin{array}{l}\text { Patentes biotecnológicas USTPO hasta } \\
\text { 1990 }\end{array}$ & 11,164 & 5 & 9 & 0 & 5 & 5 \\
\hline $\begin{array}{l}\text { Patentes biotecnológicas USTPO hasta } \\
\text { 2003 }\end{array}$ & 62,903 & 143 & 279 & 39 & 47 & 21 \\
\hline Publicaciones MEDLINE (2000** & 146,622 & $\mathrm{~s} / \mathrm{d}$ & $\mathrm{s} / \mathrm{d}$ & $\mathrm{s} / \mathrm{d}$ & 4,021 & 1,466 \\
\hline $\begin{array}{l}\text { Brecha de patentes (EUA = 100) hasta } \\
\text { 1990. }\end{array}$ & 100 & 0.04 & 0.08 & 0.00 & 0.04 & 0.04 \\
\hline $\begin{array}{l}\text { Brecha de patentes (EUA = 100) hasta } \\
\text { 2003. }\end{array}$ & 100 & 0.23 & 0.44 & 0.06 & 0.07 & 0.03 \\
\hline $\begin{array}{l}\text { Investigadores en biología por cada } \\
10,000 \text { hab. }\end{array}$ & 15 & 0.4 & $\mathrm{~s} / \mathrm{d}$ & 2 & 1 & 2 \\
\hline Empresas biotech (cada 10 mdh.) & 49 & 1 & 1 & $\mathrm{~s} / \mathrm{d}$ & 11 & 22 \\
\hline $\begin{array}{l}\text { Índice de aprovechamiento } \\
\text { (patentes/publicación)*** }\end{array}$ & 0.43 & $\mathrm{~s} / \mathrm{d}$ & $\mathrm{s} / \mathrm{d}$ & $\mathrm{s} / \mathrm{d}$ & 0.01 & 0.01 \\
\hline
\end{tabular}

*Sólo incluye empresas de biotecnología de alimentos e industriales.

**MedLINE incluye publicaciones médicas que trascienden la biología molecular y excluye otras aplicaciones no médicas, pero que dada su amplia cobertura permiten obtener un orden de magnitud de publicaciones en áreas científicas conexas a la biotecnología.

***Relación entre patentes biotecnológicas de la upsto y publicaciones de la Base Biomed disponible en la Nacional Science Fundation. ${ }^{16}$

Fuente: National Science Fundation (2006); Niosi (2005); Orozco y Olaya (2004); Bisang et al. (2006).

${ }^{16}$ Este indicador es una proxy del grado de aprovechamiento; si bien compara patentes biotecnológicas en múltiples aplicaciones con publicaciones en el área de salud (sean o no biotecnológicas), el sesgo es acotado dada la preminencia de las patentes con aplicaciones en salud. 
Junto a estos elementos de diagnóstico compartidos, es importante señalar ciertas especificidades de las trayectorias nacionales en Argentina y Brasil que evidencian diferencias en sus configuraciones institucionales.

Argentina es uno de los países de América Latina que más pronto ha generado capacidades biotecnológicas, en particular en la producción de proteínas recombinantes de aplicación terapéutica actualmente comercializadas. Hoy cuenta con una base empresarial de 84 firmas biotecnológicas, entre las cuales sólo una decena posee capacidades en moderna biotecnología (Bisang, et al., 2006). Entre ellas se destacan empresas de la industria farmacéutica con una larga tradición en biomedicina y una industria local que controla 50 por ciento del mercado. Siguen en orden de importancia el sector veterinario y los reactivos de diagnóstico. Las actividades agroalimentarias se especializan en procesos tradicionales de breeding o bioprocesamiento y utilizan la moderna biotecnología como tecnología de soporte. En ambos casos, las capacidades tienen su origen fundamentalmente en la incursión de grupos de investigación del sector público en actividades de investigación y desarrollo. ${ }^{17}$ El Consejo Nacional de Investigaciones Científicas y Tecnológicas (CONICET), el Instituto Nacional de Tecnología Agrícola (INTA) y las universidades nacionales reúnen una masa crítica de 9,500 investigadores en áreas afines a la biotecnología, con capacidad para desarrollar diferentes líneas de investigación en biotecnología vegetal y animal. ${ }^{18} \mathrm{El}$ INTA ha tenido desde sus inicios un importante papel en la adaptación a las condiciones locales y la difusión de las variedades de los principales cultivos comercializados internacionalmente. En el área de investigación, desarrolla genes propios para combatir patógenos locales y stress hídrico para los principales cultivos pampeanos y algunas producciones regionales. ${ }^{19}$ Estos desarrollos aún se encuentran en las fases

${ }^{17}$ Desde varias décadas atrás, distintas instituciones y programas públicos tuvieron como objetivo el desarrollo de un conjunto de investigaciones en diversos campos de la biología que se tradujeron, años más tarde, en avances en la producción de medicamentos, vacunas y otros productos relacionados con la salud. Actividades desarrolladas en institutos como el Malbrán, la Fundación CAMPOMAR, el CONICET), y otros organismos dependientes de universidades nacionales dan cuenta de ello. Paralelamente se registraron avances significativos en las actividades de investigación en química y en biología molecular aplicada a los cultivos vegetales, especialmente en el Instituto Nacional de Tecnología Agropecuaria (INTA) - un referente ineludible en el fitomejoramiento vegetal- y en algunas universidades nacionales.

${ }^{18}$ Desde los mencionados organismos se llevan adelante diversos proyectos de investigación en agricultura: resistencia a hongos y virus en papas y tabaco (Instituto de Investigaciones en Ingeniería Genética y Biología Molecular, INGEBI, del CONICET, resistencia a enfermedades de hongos en las frambuesas (Universidad Nacional de Tucumán), en la uva (Universidad Nacional de Cuyo), y en la cebolla (Universidad Nacional del Sur), entre otros.

${ }^{19}$ Actualmente se encuentra desarrollando técnicas de marcadores moleculares, al igual que desarrollos de genes de resistencia a hongos, a virus, a stress hídrico y a patógenos como el mal de Río Cuarto. previas en su liberación a campo. Se han realizado numerosos joint ventures entre el sector privado -transnacional y nacional- y el INTA, a fin de acelerar el proceso de lanzamiento y protección mediante patentes de estos productos.

En Brasil, al igual que en Argentina, el desarrollo de la biotecnología ha estado asociado a los esfuerzos de investigación del sector público. Sin embargo, en este caso los esfuerzos han sido sistemáticos y se han orientado estratégicamente con una activa presencia de empresas estatales. Durante los pasados veinte años, Brasil ha impulsado desde el sector público importantes inversiones para crear una masa crítica de investigadores en biotecnología, hoy compuesta por unos 20,000 especialistas.

Las actividades de ID públicas son financiadas por organismos del gobierno federal y por los distintos estados, particularmente el Consejo Nacional de Investigación y Desarrollo (CNPq) y la Fundación de Amparo a la Investigación de San Pablo (FAPESP). La FAPESP, financiada por el Estado de Sao Paulo, se ha transformado en un centro de referencia en el nivel internacional en genomas y en un modelo de investigación para los países en desarrollo. Sin laboratorios o investigadores propios, articulando una red de institutos, ha logrado importantes avances en el secuenciamiento de genomas de patógenos de cultivos locales (cítricos, azúcar), con importantes sinergias con las aplicaciones en salud. Los avances en genómica le permiten aprovechar las grandes oportunidades de desarrollos en salud y alimentos que brinda su biodiversidad.

Durante los años noventa, una activa política de incubadoras en sectores de alta tecnología resultó en una expansión significativa de la base empresarial biotecnológica. ${ }^{20}$ En 1993, Brasil contaba con 76 empresas biotecnológicas; en el año 2003, su número creció a 213 empresas, con un predominio de las aplicaciones en salud. Las mismas se localizan principalmente en el Estado de Sao Paulo y en el cluster de Minas Gerais (Biominas) (Cassiolato y Lastres, 2000).

En la actualidad, las capacidades biotecnológicas brasileñas se concentran en dos empresas públicas: la Empresa Brasileña de Investigaciones Agropecuarias (EMBRAPA) y la Fundación Oswaldo Cruz (Fiocruz); de esta última se desprenden los principales spinoffs locales en el área de medicamentos y salud humana (Derengowski Fonseca et al., 2002). También es de destacar el papel desempeñado por la Cooperativa de Productores de Azúcar y Alcohol del Estado de Sao Paulo, que cuenta con un Centro de Tecnología que desarrolla variedades propias y colabora en el Proyecto Genoma de la Caña de Azúcar. ${ }^{21}$

${ }^{20}$ Existen en Brasil 50 incubadoras de empresas tecnológicas. Entre ellas se destacan la de Minas Gerais (Biominas) y la de Río de Janeiro (Biorio).

${ }^{21}$ En este proyecto la colaboración FAPESP-COPERSUCAR involucra a más de 200 investigadores de 
Brasil y Argentina muestran una masa crítica de investigadores y empresas biotecnológicas que les permitiría insertarse no sólo como rápidos difusores de paquetes agrícolas, sino también como generadores de desarrollos propios. Sin embargo, como puede apreciarse en el cuadro 3, durante los años noventa ambos países perdieron posiciones frente al avance de otros países como China, India o Singapur, los que mostraron un fuerte crecimiento en el número de patentes biotecnológicas otorgadas por la oficina de patentes de Estados Unidos. Si bien las patentes son un indicador imperfecto de desempeño innovativo, las aplicaciones biotecnológicas son de las pocas actividades innovativas en las cuales las patentes se utilizan como formas de apropiación complementarias a otros mecanismos (secreto, marcas, lead time). Al tener en cuenta las limitaciones de estos indicadores, podemos observar que los países asiáticos redujeron la brecha a un ritmo significativamente mayor que los dos países de la región.

Un segundo aspecto asociado es la baja relación existente entre patentes biotecnológicas y publicaciones en áreas afines. Mientras que en Estados Unidos por cada patente existen algo más de dos publicaciones en disciplinas afines, en Brasil y Argentina por cada patente existen 100 publicaciones. Este desempeño adverso obedece, según varios autores, a diversos factores: el débil desarrollo de un sector de capital de riesgo que asegure el financiamiento para el nacimiento de nuevas empresas biotecnológicas; la debilidad de los mecanismos que habilitan a los científicos a colaborar con empresas, y la falta de una institucionalidad de propiedad intelectual que genere los incentivos para transformar oportunidades científicas en desarrollos patentables (Niosi y Reid, 2007; Ferrer et al., 2004).

La poca presencia de los países analizados entre los titulares de patentes biotecnológicas internacionales no es un indicador de la incapacidad de traducir avances científicos en oportunidades tecnológicas; refleja, por el contrario, la dificultad de estos países por lograr una mayor apropiación de sus desarrollos. A partir de un estudio del total de patentes otorgadas en el nivel internacional en el campo de la biotecnología entre 2000 y 2007, Brasil es titular de 82 patentes y Argentina de sólo 15. Sin embargo, inventores de estos países intervinieron en 208 y 201 patentes extranjeras respectivamente. Si bien la relación es baja en ambos casos, los inventores argentinos muestran una menor capacidad de apropiarse los desarrollos, que en 142 casos pertenecen a titulares de Estados Unidos (Centro Argentino de Información Científica y Tecnológica, САІСуT).

la red de universidades de Sao Paulo, Pernambuco y Alagoas. Fueron identificados más de 80,000 genes, muchos de ellos responsables de la resistencia a plagas y al calor, así como de la adaptación al suelo. Es el mayor proyecto de análisis de genes en plantas realizado, siendo financiado con recursos de cerca de 6 millones de dólares (Genoma España, 2005).
Desde una perspectiva diferente, otros autores sostienen que la baja presencia de titulares locales entre las patentes internacionales obedece a la inexistencia de una estrategia activa de apropiación del conocimiento por los institutos públicos de investigación (Fuck, 2007; Fuck et al., 2007). Si bien estos institutos participan activamente en la mayor parte de los procesos de ID agrícola, en los mismos predomina una visión según la cual el papel del sistema público debe limitarse a la provisión de bienes públicos en actividades en las cuales el sector privado no incursiona por los problemas de apropiabilidad del conocimiento. Sin embargo, esta visión no tiene en cuenta que en el caso de la biotecnología esta división del trabajo entre sector público y privado no es operativa: las empresas privadas hacen investigación básica y los institutos públicos realizan desarrollos de productos comercializables. Por otra parte, tratar la cuestión de la divulgación del conocimiento generado por los institutos públicos por el criterio de bienes públicos y privados es insuficiente, si tenemos en cuenta la existencia de distintas formas de apropiabilidad y de competencia desarrolladas en el seno de las economías capitalistas (Salles-Filho et al., 2000). Las distintas empresas tienen capacidades diferentes para apropiarse un nuevo conocimiento. Las más calificadas lo harán con más rapidez y éxito comercial, aumentando las asimetrías respecto a las menos calificadas. En estos casos la difusión de bienes públicos sin criterio puede resultar en una apropiación de los conocimientos por grupos locales o filiales de empresas transnacionales.

Recientemente se han implementado estrategias orientadas a reducir estas asimetrías combinando un abordaje selectivo de las alianzas público-privadas y el reforzamiento de aprendizajes institucionales en la gestión de la propiedad intelectual. Sin embargo, la configuración institucional resultante muestra especificidades según los países, que se expresan en el tipo de agente que asume el papel nodal en la alianza y las distintas modalidades de apropiación de las cuasirrentas innovativas, traduciéndose en diferentes grados de libertad del sector público para definir la estrategia tecnológica.

En Argentina, la configuración institucional es comandada por el sector privado que asume un papel central en la coordinación de una red de organismos públicos con bajos grados de articulación inicial. Actualmente, esta coordinación es asumida principalmente por empresas privadas, una empresa administradora y cofinanciadora de proyectos, formada por grandes productores agropecuarios (Bioceres, S.A.), y varios institutos científicos y tecnológicos con capacidades en biología molecular y mejoramiento convencional de semillas. Mientras que los organismos públicos realizan la totalidad de las actividades de ID, Bioceres gestiona el proyecto a partir de la constitución de fondos de inversión y lleva adelan- 
te las actividades de patentamiento nacional e internacional. Bioceres realizó convenios para el diseño de nuevas herramientas genéticas junto al CONICET y la Universidad Nacional del Litoral, y para el desarrollo de genes resistentes a patógenos locales (resistencia al mal de Río Cuarto) junto al INTA y de resistencia a sequía, junto al CONICET y la Universidad Nacional del Litoral, para ser insertados en los principales cultivos de exportación. ${ }^{22} \mathrm{Si}$ bien la propiedad intelectual es compartida, Bioceres tiene los derechos exclusivos de comercialización, los cuales pueden ser luego licenciados a compañías semilleras. ${ }^{23}$

En Brasil existe una especialización en los cultivos a los cuales se orienta la investigación en el sistema público y en el privado, con diferentes modalidades de vinculación y apropiación público-privadas. Por un lado, la investigación en los principales cultivos internacionales es dominada por las transnacionales líderes con presencia en Brasil -Monsanto, Syngenta, Dow, Bayer y Du Pont- que insertan en las variedades locales los genes desarrollados en sus casas matrices. Por otro lado, los institutos públicos se especializan en la identificación de genes y transformación de cultivos tropicales y materias primas agroindustriales a partir de alianzas con cooperativas y pequeñas empresas biotecnológicas. EMBRAPA impulsa una activa estrategia de vinculación con cooperativas y asociaciones de investigación que trabajan en el desarrollo y la difusión de nuevos cultivos, especialmente plantas tropicales que no son del interés de las empresas transnacionales. ${ }^{24}$ EMBRAPA participa igualmente en el desarrollo de cultivos controlados por las empresas transnacionales. Pero a diferencia del caso argentino, esta institución ha establecido nuevas reglas internas que priorizan la titularidad por parte de la empresa estatal de los materiales desarrollados, llevando incluso a una revisión de los acuerdos anteriores de colaboración que otorgaban la titularidad al sector privado. ${ }^{25}$ En el caso de la soya, en el que las transnacionales tienen una participación

${ }^{22}$ En el año 2004, esta red público-privada se ha ampliado con la creación del Instituto de Agrobiotecnología Rosario (INDEAR) - un joint venture entre Bioceres, s.A., el grupo local líder en biotecnología de salud Biosidus y el cONICET - que se orientará a la ID en el campo de la biología molecular, la genómica funcional y la proteómica, aplicadas a la innovación tecnológica en el sector agropecuario argentino.

${ }^{23}$ Véase www.bioceres.com.ar

${ }^{24}$ Es el caso del Proyecto Genolyptus, financiado por el Ministerio de Ciencia y Tecnología, en colaboración con siete universidades, EMBRAPA y 12 empresas privadas, en desarrollos en pulpa y papel; el mismo involucra una primera etapa de 4.1 millones de dólares, con 70 por ciento de fondos públicos y 30 por ciento del sector privado (Da Silveira et al., 2004).

${ }^{25}$ Desde 1997, EMBRAPA aplica una nueva política de propiedad intelectual. Solamente en el año 2000, la empresa realizó 16 nuevos depósitos de patentes en el Instituto de Propiedad Industrial (INPI), número bastante elevado si se compara con la cantidad de depósitos realizados entre 1973 y 1996, periodo en el cual fueron realizadas 17 solicitudes. Lo mismo se aplica a la protección de menor (aproximadamente 1/3) por las características biológicas del cultivo, EMBRAPA lleva adelante desarrollos propios que comercializa. En el caso del maíz, en el cual las transnacionales controlan 80 por ciento del mercado, la empresa pública realiza desarrollos que priorizan las características agronómicas de los productores locales y fomentan las alianzas con semilleras locales pequeñas a fin de limitar el poder de mercado de las empresas líderes (Fuck, 2007).

En este sentido Brasil muestra una mayor selectividad en cuanto a los cultivos, las trayectorias tecnológicas y las empresas hacia las cuales dirige su estrategia tecnológica. Frente a las altas barreras a la entrada existentes en biotecnologías de los principales granos, EMBRAPA y otros institutos públicos ejecutan actividades de ID de interés público, tanto en los segmentos en los que las empresas privadas no tienen interés en invertir, como en aquellos en los que la iniciativa privada es significativa. En el primer caso, combina estrategias de nicho en mercados más pequeños y segmentados, tales como el de los kidney beans, papaya o plátano, con mercados de commodities como azúcar de caña y naranjas. Esta orientación innovativa es de gran importancia si se tiene en cuenta que el nuevo paradigma se encuentra concentrado en pocos genes y cultivos, y son amplias las posibilidades a ser exploradas utilizando el nuevo conocimiento. Argentina, por su parte, está llevando investigaciones para el mejoramiento del girasol, cultivo en el que se posiciona como líder en los mercados internacionales, en alianzas público-privadas.

\section{Conclusiones}

El análisis realizado permite señalar un conjunto de condiciones que constituyen verdaderos desafíos para el desarrollo de la MB en las producciones agroalimentarias de los países de la región. Entre ellas se encuentran:

- En primer lugar, el carácter altamente multidisciplinario y complejo de la base científica de estas nuevas tecnologías, que exige mecanismos de integración de diversas áreas de conocimiento que evolucionan con rapidez.

- En segundo lugar, se trata de actividades con largos periodos de maduración e importantes inversiones en ID (unos diez años y unos 30 mi-

los nuevos cultivos desarrollados por la empresa en sus programas de mejora genética. Desde la vigencia de la Ley de Protección de Cultivos de 1997, el Servicio Nacional de Protección de Cultivos (SNPC), perteneciente al ministerio de Agricultura, ha protegido más de 200 cultivos en nombre de EMBRAPA (Genoma España, 2005). 
llones de dólares para introducir una semilla genéticamente modificada). Asociado a ello, las incertidumbres y los riesgos son muy elevados, por lo que se requieren mecanismos especiales de administración del riesgo y de aseguramiento de la apropiabilidad de los resultados.

- En tercer lugar, la estructura de los mercados de biotecnología en los países desarrollados, caracterizada por las articulaciones entre empresas especializadas en biotecnología, incumbents y universidades, y por la monetización de la propiedad intelectual, con la participación de los mercados de capitales (capitales de riesgo, public equity) -proceso conceptualizado como de "industrialización del conocimiento"-, no es fácilmente reproducible en los países de la región.

- En cuarto lugar, los procesos de aprendizaje presentan fuertes complementariedades con las tecnologías tradicionales y con otros activos complementarios, los que tienen un papel importante tanto en la generación como en la apropiación de las cuasirrentas de innovación. El control de estos activos - entre los que se encuentran las capacidades productivas y el manejo de las tecnologías tradicionales y de los canales de distribución, las capacidades de gestión del acceso a los mercados y el gerenciamiento de la información y del marketing- es uno de los mecanismos fundamentales para la apropiación de las cuasirrentas de innovación.

A pesar de estas condiciones y del carácter aún incipiente de los desarrollos de la moderna biotecnología, el nuevo paradigma tecnológico ha comenzado a tener un impacto profundo sobre la economía y la sociedad, y sus potencialidades son muy amplias.

La MB ha comenzado a difundirse, en forma parcial, en algunos países de América Latina, de la mano de las grandes ETN, incidiendo en las dinámicas innovativas, trayectorias y alcances en los mismos. La difusión de "paquetes (bio) tecnológicos", desarrollados y controlados en su gran mayoría por ETN, ha posibilitado aumentos de la producción, la productividad y la competitividad en los sectores de aplicación. Se ha traducido, asimismo, en la reconfiguración de los mercados de insumos y en la transformación de la agricultura en un sector basado en desarrollos científicos -dada la importancia creciente delos avances de la ingeniería genética y de la genómica en la identificación de nuevas características agronómicas- aun cuando estos desarrollos sean muy limitados en la región.

Algunas lecciones de importancia pueden extraerse de la experiencia de los desarrollos recientes de la agrobiotecnología en los países analizados:
- La difusión de "paquetes tecnológicos" cerrados, fuertemente protegidos por derechos de propiedad intelectual y por costosos derechos "institucionales" para su aprobación y aceptación en los mercados de destino de los diferentes países, no conduce necesaria ni automáticamente a desarrollos locales importantes en ciencia y tecnología. Por el contrario, al limitar los encadenamientos a las actividades de provisión de insumos fuertemente globalizados se desaprovechan las posibilidades de diversificación y articulación con los sistemas nacionales de innovación, con lo que refuerzan un patrón de especialización basado en la explotación y exportación de recursos naturales con escaso grado de elaboración local (commodities).

- Por otra parte, el paso de la biotecnología tradicional a la moderna no es asimilable a un proceso automático de upgrading, sino que requiere de capacidades locales en ciencia y tecnología - individuales, sistémicas y organizacionales - que permitan a las empresas locales acceder a la amplia gama de disciplinas conexas a la biotecnología e integrarlas.

- La situación actual de los países analizados en este artículo en relación con la MB pone en evidencia que, a pesar de la existencia de una significativa brecha (bio) tecnológica tanto en relación con los países industrializados como con otros países emergentes, han logrado construir una importante base de conocimiento en biotecnología. Argentina y Brasil, dos de los mayores países de la región, cuentan con abundantes recursos naturales, una importante base de recursos humanos calificados, una base mínima de empresas biotecnológicas, una infraestructura pública en ciencia y tecnología en desarrollo, sistemas de bioseguridad y avances en la configuración de los derechos de propiedad intelectual. En el caso de Brasil, y en menor medida de la Argentina, estos elementos convergen en la conformación de una plataforma inicial para impulsar la generación y el desarrollo local de la MB.

¿Cómo transitar hacia una estrategia tecnológica que concilie la necesidad de insertarse en "mercados de know how" con el desarrollo de capacidades locales en agrobiotecnología en un sendero de desarrollo? ¿Cómo transformarse de meros adaptadores o proveedores de activos tecnológicos aislados en estos mercados en generadores de nuevos procesos y productos que contemplen las prioridades económicas y sociales estratégicas de estos países?

Éstos son, entre otros, interrogantes cuya respuesta trasciende la dinámica de las aplicaciones agrícolas de la biotecnología, que exigen el análisis conjun- 
to de éstas con el de las trayectorias tecnológicas de los sistemas agroalimentarios y de la biomedicina local -fuente fundamental de sinergias en el contexto de un paradigma caracterizado por la alta transversalidad de sus oportunidades-.En un ámbito más general, son interrogantes que deben encontrar respuestas en el marco estratégico del desarrollo científico y tecnológico de estos países.

\section{REFERENCIAS BibLIOGRÁFICAS}

AAPRESID (Asociación Argentina de Productores en Siembra Directa). Disponible en: www.aapresid.com.ar

Arundel, A., G. Crespi y P. Patel (2006), Biotechnology. Scoping Paper Europe Innova

ASA (Asociación de Semilleros Argentinos), 2008. Disponible en: www.asa.com.ar

Bisang, R., G. Gutman, P. Lavarello, S. Sztulwark, y A. Díaz, (comps.) (2006), Biotecnología y desarrollo. Un modelo para armar en la economía argentina. Buenos Aires: Prometeo y ungs.

—, R., y L. Varela (2006), "Panorama internacional de la biotecnología en el sector agrario. Dinámica de las megaempresas internacionales de agrobiotecnología e impacto sobre la oferta local”. En Bisang, Gutman, Lavarello, Sztulwark y Díaz, A. (comps.), Biotecnología y desarrollo. Un modelo para armar en la economía argentina. Buenos Aires: Prometeo y UNGS.

Brookes, G., y P. Barfoot (2005), "GM Crops: The Global Economic and Environmental Impacts-The First Nine Years, 1996-2004”. AgBioForum 8 (2 y 3): 187-196.

CAICyT (Centro Argentino de Información Científica y Tecnológica). Disponible en: www. caicyt.gov.ar

Cassiolato, J., y H. Lastres (2000), "Local Systems of Innovation in Mercosur Countries". Industry and Innovation 7 (1): 33-53

Chataway, J., J. Tait, y D. Weit (2003), "Understanding R\&D Strategies in Agrofood Biotechnology: Trajectories and Blind Pots". Innogen Working Paper. Junio, 2003.

Christensen, J. (2003), "Introduction: The Industrial Dynamics of Biotechnology: New Insights and New Agendas". Industry and Innovation 10 (3): 223-230.

Da Silveira J., M. Dal Poz, y A. Assad (coords.) (2004), Biotecnología e recursos genéticos. Desafios e oportunidades para o Brasil. Campinas: UNICAMP, FINEP.

Derengowski Fonseca, M. J. Silbeira, y S. Salles-Filho (2002), "The Development of Biotechnology in Brazil.” En Janardlhan Rao, N., The Business Side of Biotechnology. Uttarakhand, India: ICFAI, University.

Díaz, A., y D. Golombek, ADN, 50 años no es nada. Buenos Aires: Siglo XXI.

Dosi, G. (1988), "Sources, Procedures and Economic Impacts of Innovation". Journal of Economic Evolution, vol. xxvI (septiembre): 1120-1171.
Ducos, Ch., y P. Joly, (1988), Les biotechnologies. París: La Découverte.

EC, (2007), "Consequences, Opportunities and Challenges of Modern Biotechnology in Europe”. En Zika, E. Papatryfon, O. Wolf, M. Gómez-Barbero, A. Stein, y A. Bock, 2 Institute for Prospective Technological Studies, European Communities, European Commission, JRC Reference Reports, Luxemburgo.

EuropaBio (2005), Biotechnology in Europe 2005. Comparative Study. Lyon: BioVision. Ferrer, M., H. Thorsteindóttir, U. Quach, A. Daar, y P. Singer, (2004), "The Scientific Muscle of Brazil's Health Biotechnology". Nature Biotechnology 22, suplemento, diciembre.

Fransman, M. (1994), Biotechnology Generation, Diffusion and Policy: An Interpretive Survey. Working Paper no. 1. Maastricht: United Nations, University Institute for New Technologies (ONU/INTECH).

Fuck, M. (2007), "Os novos caminhos das Instituições Públicas de Pesquisa Agropecuária: observações a partir dos casos da EMBRAPA e do INTA”. XII Seminario ALTEC, Argentina.

, M. Bonacelli, y S. Carvalho (2007), “A pesquisa agropecuária frente as novas tecnologias: da complementaridade entre as actividades públicas e privadas à ocupação de espaços estratégicos". XV Congreso da sober "Conhecimentos para Agricultura do Futuro”. Londrina, 22 a 25 de julho de 2007, Sociedad Brasileña de Economía, Administración Sociología Rural.

Genoma España Hiprerion Biotech-Trikarty (2005), Situación actual y oportunidades de negocios en el sector biotecnológico en América Latina. España: Genoma España Hiprerion Biotech-Trikarty.

Goodman, D., B. Sorj., y Wilkinson (1987), From Farming to Biotechnology. Reino Unido: Basil Blackwell.

Gutman, G., P. Lavarello, S. Rotondo, y G. Yoguel (2008), La industria de maquinaria agrícola en Argentina: dinámica reciente, capacidades innovativas, empleo y comercio exterior. Buenos Aires: Ministerio de Trabajo, Empleo y Seguridad Social. En prensa.

_ y P. Lavarello (2008), Oportunidades de la moderna biotecnología para la diversificación de los sistemas agroalimentarios en América Latina. Documento de trabajo. Santiago de Chile: CEPAL, Naciones Unidas.

- y J. Cajal (2006 a), "La biotecnología y las industrias de ingredientes alimentarios en Argentina". Journal of Technology Management \& Innovation I (3): 121-130.

— $—$, y —— (2006b), "Biotecnología y alimentación. Estrategias de las empresas transnacionales de ingredientes alimentarios". En Bisang, R., G. Gutman, P. Lavarello, S. Sztulwark, y A. Díaz, (comps.), op. cit. 
y D. Roisinblit (2006), "La promoción pública de actividades de investigación y desarrollo en biotecnología en Argentina”. En Bisang, R., G. Gutman, P. Lavarello, S. Sztulwark, y A. Díaz, (comps.), op. cit.

IICA (2004), Situación y perspectivas de la agricultura y la vida rural en las Américas. San José, Costa Rica: Instituto Interamericano de Cooperación para la Agricultura (IICA) INDEC (Instituto Nacional de Estadística y Censos). Disponible en: www.indec.gov.ar James, C. (2006), "Global Status of Commercialized Biotech/GM Crops: 2006". En International Service for the Acquisition of Aagri-Biotech Applications (ISAAA) núm. 36. Ithaca, Nueva York: ISAAA Brief.

Malerba, F., y L. Orsenigo, (2002), "Innovation and Market Structure in the Dynamics of the Pharmaceutical Industry and Biotechnology: towards an History-Friendly Model". Industrial and Corporate Change 11(4): 667-703.

Maroni, J. (1999), "La maquinaria agrícola y el cultivo de soya en la Argentina". Argentina: AGROMENSAJES. Publicación cuatrimestral de la Facultad de Ciencias Agrarias - UNR, núm. 12.

National Science Foundation (2006), "Science and Engineering Indicators 2006". Disponible en: http://www.nsf.gov/statistics/seind06/pdf_v2.htm\#c5

Niosi, J. (2005), "La biotechnologie en Amérique Latine". En La chronique des Amériques. Montreal: Centre d'Études internationales et Mondialisation. Université du Québec. Diciembre.

_ Technologies as Windows of Opportunity for LDCS?". World Development 35 (3): 426-438.

OCDE (2006), Biotechnology Statistics. París: OCDE.

Oehmke, J., y C. Wolf (2003), "Measuring Concentration in the Biotechnology R\&D Industry: Adjusting for Interfirm Transfer of Genetic Materials". AgBioForum 6 (3): 134-140.

Orozco, L., y D. Olaya (2004), Indicadores del Programa Nacional de Biotecnología. Colombia: Observatorio Colombiano de Ciencia y Tecnología.

Orsenigo, L. (1999), The Emergence of Biotechnology. Nueva York: St Martin's Press.

Orsi, F., y B. Coriat (2003), "Droits de Propriété Intellectuelle, Marchés Financiers et Innovation. Une configuration soutenable?”. La Lettre de la Régulation. Julio.

Pavitt, K. (1984), "Sectoral Patterns of Technical Change: Towards a Taxonomy and a Theory". Research Policy, 13: 343-374.

Pisano, G. (2006), Science Business. The Promise, the Reality and the Future of Biotech Boston, Massachusetts: Harvard Business School.

Possas, M., S. Salles-Filho, y J. Silveira (1996), “An Evolutionary Approach to Technological Innovation in Agriculture: Some Preliminary Remarks". Research Policy
25 (septiembre) 933-945.

Qaim, M., y G. Traxler, (2002), Roundup Ready soybeans in Argentina: Farm level, environmental, and welfare effects. 6a. Conferencia Internacional ICABR, Ravello, Italia.

RICYT (2008), Red de Indicadores de Ciencia y Tecnología-Iberoamericana e Interamericana. Disponible en: http://www.ricyt.edu.ar/

Salles-Filho, S., et al. (coord.) (2000), Ciência, tecnologia e innovaçao - a reorganizaçao da pesquisa pública no Brasil. Campinas: UNICAMP.

_ (coord.) (2007), "Innovation and Intellectual Property in the Latin American Agricultural Sector: an Introductory Overview for Argentina, Brazil and Colombia". Documento de trabajo. Santiago de Chile: CEPAL.

Schimmelpfennig, D., y J. King (2004), "Mergers, Acquisitions and Flows of Agbiotech Intellectual Property". International Consortium on Agricultural Biotechnology Research (ICABR) 8th ICABR. International Conference on Agricultural Biotechnology: International Trade and Domestic Production. Ravello (Italia), julio, pp. 8-11.

Trigo E., G. Traxler, C. Pray, y R. Echeverría (2002), Biotecnología agrícola y desarrollo rural en America Latina y el Caribe. Implicaciones para el financiamiento del $B I D$. Washington: BID.

Valentin F., y R. Jensen (2003), "Discontinuities and Distributed Innovation: The Case of Biotechnology in Food Processing”. Industry and Innovation 10 (3): 275-340.

Von Beuzekom, B., y A. Arundel (2006) Biotechnology Statistics. París: OCAE.

Ward, M. (2000), "Emerging Competition Policy Issues in Agricultural Biotechnology". American Behavioral Scientist 44: 504. Sage Publications. Disponible en: http:// abs.sagepub.com/cgi/content/abstract/44/3/504

Wilkinson, J. (1998), "The R\&D Priorities of Leading Food Firms and Long-Term Innovation in the Agrofood System". International Journal of Technology Management 16 (7): 711-720. 